\title{
Correlation between seizure characteristics and quality of life in epilepsy patients
}

\author{
Rizaldy Taslim Pinzon', Rosa De Lima Renita Sanyasi ${ }^{2}$, Jesisca Tandora ${ }^{3}$, \\ Andre Dharmawan Wijono ${ }^{4}$, Fransiscus Buwana ${ }^{5}$ \\ 1,2,3,4,5 Department of Neurology, Faculty of Medicine Duta Wacana Christian University, Yogyakarta, Indonesia
}

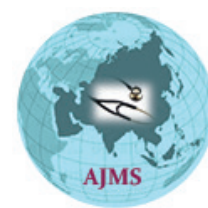

A B S TR A C T

Background: Epilepsy is one of the most common neurological disorder and characterized by recurrent seizures caused by abnormal electrical activity in the brain. Epilepsy is both a medical diagnosis and a social label that can negatively impact quality of life (QoL). Aims and Objective: This study aimed to evaluate the correlation between characteristics of seizure and QoL among epilepsy patients. Materials and Methods: This is a case series study conducted at Bethesda Hospital, Yogyakarta. Subjects answer 8 questions in the SF-8 questionnaire by choosing one from several alternative answers. Sub-scale assessed in this questionnaire including general health perception $(\mathrm{GH})$, physical functioning (PF), physical role functioning (RP), bodily pain (BP), vitality (VT), social role function (SF), mental health $(\mathrm{MH})$, and emotional role functioning (RE). Each answer will be score and processed in a program from Optum ${ }^{\mathrm{Tm}}$. The final results will be summarized into physical component (PCS) and mental component (MCS). Results: Total of the subjects were 27. Subjects were dominated by male, age $<60$ years. The highest score is on the bodily pain subscale (mean: $50.00 \pm 8.0739$ ), wherease the lowest score is on global health perception (mean: $43.95 \pm 7.1970$ ). Overall, subjects in this study have a better mental status than physical status (47.14 \pm 10.2093 vs $46.90 \pm 7.9418$ ). Type of seizure (PCS p: 0.794; MCS p:0.093), duration of epilepsy(PCS p: 0.832; MCS p: 0.856), history of epileptic status (PCS p: 0.141; MCS p: 0.951), the presence of neurological deficit (PCS p: 0.140; MCS p: 0.283), frequency of seizure before treatment (PCS p: 0.648; MCS p: 0.213), frequency of seizure after treatment (PCS p: 0.249; MCS p: 0.407), and frequency of seizure within the last 1 year were not significant to influence the QoL (PCS p:0.978; MCS p: 0.513). Conclusion: There is no significant characteristics of seizure that influence the QoL.

Access this article online

Website:

http://nepjol.info/index.php/AJMS DOI: 10.3126/ajms.v9i6.20672 E-ISSN: 2091-0576

P-ISSN: 2467-9100

Key words: Epilepsy; Quality of life; SF-8 questionnaire; Seizure

\section{INTRODUCTION}

Epilepsy is a disorder of the central nervous system characterized by periodic loss of consciousness with or without convulsions associated with abnormal electrical activity in the Bram. ${ }^{1}$ It is estimated that 50 million individuals worldwide have epilepsy and about $90 \%$ of them are from developing countries. ${ }^{2,3}$ The incidence of epilepsy is around 50 per 100,000 per year and do affect between 5 and 10 people per 1000 in developed country. ${ }^{4,5}$ Asia has $17.0 \%$ higher burden than Africa from neuropsychiatric conditions (including epilepsy). In comparison to Africa, Asia has more untreated patients,
$55.0 \%$ more additional epilepsy cases every year, because of its larger population. ${ }^{6}$

Epilepsy is both a medical diagnosis and a social label because people with epilepsy face many psychosocial challenges (anxiety, social stigma, difficulty in driving, unemployment) that can negatively impact quality of life (QoL). ${ }^{7}$ Epilepsy is a multifaceted chroinic disorder which has diverse and complex effects on the well-being of the patients. ${ }^{8}$ Previous study showed QoL was significantly worse in patients with epilepsy than in the healthy population in many factors and it had similar QoL with the healthy population when patients with epilepsy are well- 
controlled. ${ }^{9-11}$ Improving the QoL is the most important goal of epilepsy Management. ${ }^{12}$ The burdens of epilepsy to an affected person include physical hazards from the seizure itself and also social discrimination as a result of negative attitudes towards people with epilepsy. ${ }^{4}$ This study aimed to identify the correlation between seizure characteristics and QoL in epilepsy patients.

\section{MATERIALS AND METHODS}

\section{Subject}

This is a case series study. This study has been done on December 2017 to January 2018 at Neurology Clinic, Bethesda Hospital, Yogyakarta, Indonesia. Inclusion criteria of the subjects i.e.: (i) adult (age $>18$ years), (ii) an outpatient at Bethesda Hospital, (iii) diagnosed epilepsy $\geq 6$ months, and (iv) have a routine epilepsy treatment. Every subjects who refused to be included in this study and have a disability caused by major health problem (stroke, chronic heart failure, chronic kidney disease, chronic pulmonary obstructive disease, cancer, dementia, severe mental disability) will be excluded.

\section{Variables}

The variables assessed in this study include: age, gender, educational background (no education, elementary school, junior high school, senior high school, or bachelor degree), family history of epilepsy (with or without family history of epilepsy), etiology of epilepsy (cerebrovascuar accident [CVA] or idiopathic), electroencephalography (EEG) test (abnormal or normal), and CT Scan examination (no abnormalities or CVA).

Characteristics of seizure assessed in this study including: type of seizure (simple partial seizure, complex partial seizure, general tonic clonic seizure, or abscence seizure), the presence of neurological deficit (yes or no), history of epileptic status (yes or no), frequency of seizure before treatment (1 times/ month, 1-3 times/month, 4-10 times/month, or $>10$ times/ month), frequency of seizure after treatment (never, 1-3 times/month, 4-10 times/month, or $>10$ times/month), and frequency of seizure within the last 1 year (at least once/ month, 4-11 times/month, 1-3 times/month, or never). Subjects' QoL measured by using SF-8 questionnaire.

SF-8 questionnaire used after obtained a permission from Optum $^{\mathrm{TM}}$. It consist of 8 question about daily physical and mental status. Subjects asked to answer the questions by choosing one from several alternative answers.Subscale assessed in this questionnaire including general health perception $(\mathrm{GH})$, physical functioning $(\mathrm{PF})$, physical role functioning (RP), bodily pain (BP), vitality (VT), social role function $(\mathrm{SF})$, mental health $(\mathrm{MH})$, and emotional role functioning (RE).Each answer will be scored and processed in a program from Optum ${ }^{\mathrm{TM}}$. The final results will be summarized into physical component (PCS) and mental component (MCS). There is no spesific classification to interprete the SF-8 score. A higher score indicates a better QoL.

\section{Statistical analysis}

All variables are analyzed using SPSS programme. Univariat analysis is performed to find out subjects' characteristics. All SF-8 subscale score will be assessed for normality. After calculating for normality, variables will be analyzed using independentt-test, Kruskal-Wallis test,or Mann-Whitney $\mathrm{U}$ test for determine a significant factor(s) to QoL.The significant was set at $\mathrm{p}<0.05$.

\section{Ethical clearance}

This study is approved by Ethics Committee of Duta Wacana Christian University, Yogyakarta, Indonesia. The number of ethical clearance letter is 583/C.16/FK/2018.

\section{RESULTS}

Total of the subjects were 27. Table 1 shows subjects' characteristics. Subjects were dominated by male, age $<60$ years, senior high school as the last educational background, and do not have a family history of epilepsy. The underlying cause of epilepsy in the most of subjects is CVA and it was confirmed by CT Scan examination. About $88.9 \%$ of the subjects have an abnormal result on EEG.

Table 2 shows the detail of characteristics of seizure. Twenty three subjects $(85.2 \%)$ have a general tonic

\begin{tabular}{|c|c|c|}
\hline Characteristics & $\mathbf{n}$ & $\%$ \\
\hline \multicolumn{3}{|l|}{ Gender } \\
\hline Male & 14 & 51.9 \\
\hline Female & 13 & 48.1 \\
\hline \multicolumn{3}{|c|}{ Age (mean: $55.67 \pm 17.515)$} \\
\hline$\geq 60$ years & 12 & 44.4 \\
\hline$<60$ years & 15 & 55.6 \\
\hline \multicolumn{3}{|c|}{ Educational background } \\
\hline No education & 1 & 3.7 \\
\hline Elementary school & 3 & 11.1 \\
\hline Junior high school & 3 & 11.1 \\
\hline Senior high school & 11 & 40.7 \\
\hline Bachelor degree & 9 & 33.3 \\
\hline \multicolumn{3}{|c|}{ Family history of epilepsy } \\
\hline Yes & 3 & 11.1 \\
\hline No & 24 & 88.9 \\
\hline \multicolumn{3}{|l|}{ Etiology of epilepsy } \\
\hline Idiopathic & 8 & 29.6 \\
\hline CVA & 19 & 70.4 \\
\hline \multicolumn{3}{|l|}{ CT Scan } \\
\hline CVA & 19 & 70.4 \\
\hline No abnormalities & 8 & 29.6 \\
\hline \multicolumn{3}{|l|}{ EEG test } \\
\hline Abnormal & 24 & 88.9 \\
\hline Normal & 3 & 11.1 \\
\hline
\end{tabular}

Asian Journal of Medical Sciences | Nov-Dec 2018 | Vol 9 | Issue 6 
clonic seizure. More than $50 \%$ of the subjects have been diagnosed epilepsy in the last 5 years with neurological deficit. There was an improvement in epilepsy symptom based on the frequency of seizure, compared between before and after treatment. Before treatment, most of the subjects had a seizure more than once per month. After treatment, most of the subjects only have a seizure once per month $(55.6 \%)$.

The highest score is on the bodily pain subscale (mean: $50.00 \pm 8.0739$ ), where as the lowest score is on global health perception (mean: $43.95 \pm 7.1970)$. Overall, subjects in this study have a better mental status than physical status (47.14 \pm 10.2093 vs $46.90 \pm 7.9418)$ (Table 3).

Table 4 and 5 show the result of analysis on each variable. Male, age $\geq 60$ years, and CVA as the etiology of epilepsy has a worse QoL compared with female, age $<60$ years and epilepsy with unknown etiology.Subjects with elementary school as the last educational background have the best PCS score, whereas subjects with bachelor degree have the best MCS score, but it was not significant. Subjects with family history of epilepsy have a worse mental component and it was statistically significant $(\mathrm{p}<0.021)$.

Subjects with history of epileptic status (PCS: $47.84 \pm$ 2.935, MCS: $48.18 \pm 3.068$ ) and do not have a neurological deficit (PCS: $50.40 \pm 6.795$, MCS: $50.45 \pm 8.010$ ) have a betterQoL score than subjects without history of epileptic status and have a neurological deficit. Subjects with a simple partial seizure have the worst PCS score (41.01 \pm 17.684), whereas subject with absence seizure has the best PCS score (50.77). Otherwise, subject with absence seizure has the worst MCS score (32.90), whereas subjects with simple partial seizure have the best MCS score (60.32 \pm 1.824). Subjects who suffered from epilepsy for $2-5$ years (PCS: $50.93 \pm 7.405$, MCS: $49.36 \pm 5.263$ ) and only have a seizure once per month before treatment (PCS: 49.05 \pm 8.924, MCS: $52.41 \pm 6.647$ ) have the best QoL. There are no significant seizure characteristics affecting QoL in epilepsy patients.

\section{DISCUSSION}

This study showed that male subjects (PCS: $44.67 \pm 6.533$, MCS: $46.11 \pm 9.250$ ), age $\geq 60$ years (PCS: $44.26 \pm 6.471$, MCS: $42.04 \pm 10.282$ ), and CVA as the etiology of epilepsy (PCS: $45.42 \pm 8.086$, MCS: $45.75 \pm 10.894$ ) have a worse QoL score on both PCS and MCS. The correlation between age with QoL was not significant. It was a same result with study by Milovanovic, et al. ${ }^{13}$, but this finding is contrary to previous studies.Older ages is a potential predictors of worse QoL in adult patients with epilepsy. ${ }^{14}$ In a study

\begin{tabular}{|c|c|c|}
\hline Characteristics & $\mathbf{n}$ & $\%$ \\
\hline \multicolumn{3}{|l|}{ Type of seizure } \\
\hline Simple partial seizure & 2 & 7.4 \\
\hline Complex partial seizure & 1 & 3.7 \\
\hline General tonic clonic seizure & 23 & 85.2 \\
\hline Absence seizure & 1 & 3.7 \\
\hline \multicolumn{3}{|l|}{ History of epileptic status } \\
\hline Yes & 3 & 11.1 \\
\hline No & 24 & 88.9 \\
\hline \multicolumn{3}{|l|}{ Duration of epilepsy } \\
\hline$>10$ years & 4 & 14.8 \\
\hline $6-10$ years & 7 & 25.9 \\
\hline $2-5$ years & 8 & 29.6 \\
\hline$\leq 1$ year & 8 & 29.6 \\
\hline \multicolumn{3}{|l|}{ Neurological deficit } \\
\hline Yes & 19 & 70.4 \\
\hline No & 8 & 29.6 \\
\hline \multicolumn{3}{|c|}{ Frequency of seizure before treatment } \\
\hline$>10$ times/month & 2 & 7.4 \\
\hline 4-10 times/month & 8 & 29.6 \\
\hline 1-3 times/month & 6 & 22.2 \\
\hline 1 times/month & 11 & 40.7 \\
\hline \multicolumn{3}{|c|}{ Frequency of seizure after treatment } \\
\hline 4-10 times/month & 1 & 3.7 \\
\hline $1-3$ times/month & 11 & 40.7 \\
\hline 1 times/month & 15 & 55.6 \\
\hline \multicolumn{3}{|c|}{ Frequency of seizure within the last 1 year } \\
\hline At least once/month & 1 & 3.7 \\
\hline 4-11 times/month & 3 & 11.1 \\
\hline 1-3 times/month & 4 & 14.8 \\
\hline Never & 19 & 70.4 \\
\hline
\end{tabular}

\begin{tabular}{lccc}
\multicolumn{4}{l}{ Table 3. Score of Quality of Life } \\
\hline Sub-Scale & Mean (SD) & $\begin{array}{c}\text { Minimum } \\
\text { Score }\end{array}$ & $\begin{array}{c}\text { Maximum } \\
\text { Score }\end{array}$ \\
\hline GH & $43.95 \pm 7.1970$ & 32.56 & 59.45 \\
PF & $45.67 \pm 8.8872$ & 21.46 & 54.05 \\
RP & $46.89 \pm 7.7885$ & 28.32 & 53.98 \\
BP & $50.00 \pm 8.0739$ & 40.07 & 60.77 \\
VT & $49.82 \pm 10.2628$ & 28.14 & 61.83 \\
SF & $46.82 \pm 9.1817$ & 23.44 & 55.25 \\
RE & $44.12 \pm 7.7381$ & 29.25 & 52.42 \\
MH & $47.52 \pm 9.2102$ & 21.40 & 56.79 \\
PCS & $46.90 \pm 7.9418$ & 28.51 & 57.32 \\
MCS & $47.14 \pm 10.2093$ & 20.15 & 61.61 \\
\hline
\end{tabular}

SD: Standard Deviation, GH: general health perception, PF: physical functioning, RP: physical role functioning, BP: bodily pain, VT: vitality, SF: social role function, $\mathrm{MH}$ : mental health, RE: emotional role functioning, PCS: physical component, MCS: mental component

conducted in Cluj-Napoca, age was negatively correlated with almost all QoL in epilepsy items $(\mathrm{p}<0.05) .{ }^{15}$

The correlation between gender etiology of epilepsy with QoL in this study were not significant. It is similar to previous studiesstated patient's sex did not influenced patients' QoL $(\mathrm{p}<0.05){ }^{13,15}$

Subjects with elementary school as the last educational background have the best PCS score (49.92 \pm 6.405), whereas subjects with bachelor degree have the best 


\begin{tabular}{|c|c|c|c|c|}
\hline \multirow[t]{2}{*}{ Characteristics } & \multicolumn{2}{|c|}{ PCS } & \multicolumn{2}{|c|}{ MCS } \\
\hline & Mean (SD) & $p$ & Mean (SD) & $p$ \\
\hline \multicolumn{5}{|l|}{ Gender } \\
\hline Male & $44.67 \pm 6.533$ & 0.133 & $46.11 \pm 9.250$ & 0.595 \\
\hline Female & $49.29 \pm 8.854$ & & $48.26 \pm 11.425$ & \\
\hline \multicolumn{5}{|l|}{ Age } \\
\hline$\geq 60$ years & $44.26 \pm 6.471$ & 0.126 & $42.04 \pm 10.282$ & 0.017 \\
\hline$<60$ years & $49.00 \pm 8.575$ & & $51.23 \pm 8.383$ & \\
\hline \multicolumn{5}{|c|}{ Educational background } \\
\hline No education & 42.13 & 0.917 & 46.19 & 0.751 \\
\hline Elementary school & $49.92 \pm 6.405$ & & $38.78 \pm 16.346$ & \\
\hline Junior high school & $48.00 \pm 9.956$ & & $45.38 \pm 11.177$ & \\
\hline Senior high school & $46.09 \pm 7.653$ & & $48.66 \pm 6.604$ & \\
\hline Bachelor degree & $47.04 \pm 9.438$ & & $48.77 \pm 12.349$ & \\
\hline \multicolumn{5}{|c|}{ Family history of epilepsy } \\
\hline Yes & $47.75 \pm 2.708$ & 0.848 & $34.58 \pm 15.349$ & 0.021 \\
\hline No & $46.79 \pm 8.399$ & & $48.71 \pm 8.612$ & \\
\hline \multicolumn{5}{|l|}{ Etiology of epilepsy } \\
\hline Idiopathic & $50.40 \pm 6.795$ & 0.140 & $50.45 \pm 8.010$ & 0.283 \\
\hline CVA & $45.42 \pm 8.086$ & & $45.75 \pm 10.894$ & \\
\hline \multicolumn{5}{|l|}{ EEG test } \\
\hline Abnormal & $46.64 \pm 8.363$ & 0.649 & $47.36 \pm 10.349$ & 0.760 \\
\hline Normal & $48.92 \pm 2.942$ & & $45.40 \pm 10.866$ & \\
\hline
\end{tabular}

SD: Standard Deviation, PCS: physical component, MCS: mental component, CVA: Cerebrovascular Accident, EEG: electroencephalography

\begin{tabular}{|c|c|c|c|c|}
\hline \multirow[t]{2}{*}{ Characteristics } & \multicolumn{2}{|c|}{ PCS } & \multicolumn{2}{|c|}{ MCS } \\
\hline & Mean (SD) & $\mathbf{p}$ & Mean (SD) & $p$ \\
\hline \multicolumn{5}{|l|}{ Type of seizure } \\
\hline General tonic clonic seizure & $47.08 \pm 7.475$ & 0.794 & $46.38 \pm 9.801$ & 0.093 \\
\hline Absence seizure & 50.77 & & 32.90 & \\
\hline Complex partial seizure & 50.47 & & 52.59 & \\
\hline \multicolumn{5}{|l|}{ History of epileptic status } \\
\hline Yes & $47.84 \pm 2.935$ & 0.832 & $48.18 \pm 3.068$ & 0.856 \\
\hline No & $46.78 \pm 8.391$ & & $47.01 \pm 10.809$ & \\
\hline \multicolumn{5}{|l|}{ Duration of epilepsy } \\
\hline$>10$ years & $46.39 \pm 9.208$ & 0.141 & $48.32 \pm 3.163$ & 0.951 \\
\hline $6-10$ years & $47.94 \pm 5.808$ & & $44.90 \pm 11.321$ & \\
\hline $2-5$ years & $50.93 \pm 7.405$ & & $49.36 \pm 5.263$ & \\
\hline$\leq 1$ year & $42.20 \pm 8.311$ & & $46.31 \pm 15.266$ & \\
\hline Yes & $45.42 \pm 8.086$ & 0.140 & $45.755 \pm 10.894$ & 0.283 \\
\hline No & $50.40 \pm 6.795$ & & $50.45 \pm 8.010$ & \\
\hline \multicolumn{5}{|c|}{ Frequency of seizure before treatment } \\
\hline$>10$ times/month & $45.67 \pm 6.788$ & 0.648 & $49.51 \pm 4.355$ & 0.213 \\
\hline 4-10 times/month & $45.55 \pm 7.194$ & & $42.02 \pm 11.458$ & \\
\hline 1-3 times/month & $45.14 \pm 8.339$ & & $43.55 \pm 8.339$ & \\
\hline 1 times/month & $49.05 \pm 8.924$ & & $52.41 \pm 6.647$ & \\
\hline \multicolumn{5}{|c|}{ Frequency of seizure after treatment } \\
\hline 4-10 times/month & 50.77 & 0.249 & 32.90 & 0.407 \\
\hline 1-3 times/month & $44.342 \pm 7.296$ & & $47.08 \pm 7.281$ & \\
\hline 1 times/month & $48.51 \pm 8.372$ & & $48.14 \pm 11.837$ & \\
\hline \multicolumn{5}{|c|}{ Frequency of seizure within the last 1 year } \\
\hline At least once/month & 45.53 & 0.978 & 50.71 & 0.513 \\
\hline 4-11 times/month & $45.21 \pm 11.863$ & & $38.92 \pm 11.863$ & \\
\hline 1-3 times/month & $48.07 \pm 2.651$ & & $42.34 \pm 15.412$ & \\
\hline Never & $46.99 \pm 8.905$ & & $49.27 \pm 8.569$ & \\
\hline
\end{tabular}

SD: Standard Deviation, PCS: physical component, MCS: mental component

MCS score $(48.77 \pm 12.349)$. There was no statistically significant between educational background with QoL (PCS p: 0.917; MCS p: 0.751). This finding is similar to study by Milovanovic, et al. ${ }^{13}$ showed sociodemographic factors (including education) did not significantly predict quality of life in epilepsy (QOLIE)-31 score. In contrast, Asian Journal of Medical Sciences | Nov-Dec 2018 | Vol 9 | Issue 6 
Onwuekwe, et al. ${ }^{16}$ stated psychological wellbeing had a positive correlation with education level. Education appeared to be most strongly associated with QoL at the high school and college levels. Lower educational attainment level was observed to have an independent, negative association with QOLIE $(\mathrm{p}<0.05) .{ }^{17}$

Subjects with family history of epilepsy have a worse mental component. It was the only statistically significant variable related to QoL $(p<0.021)$. However, Melikyan, et al. ${ }^{14}$ mention family status did not significantly affect health-related qulity of life (HRQOL).

Type of seizure (PCS p: 0.794; MCS p:0.093), duration of epilepsy(PCS p: 0.832; MCS p: 0.856), history of epileptic status (PCS p: 0.141; MCS p: 0.951), the presence of neurological deficit (PCS p: 0.140; MCS p: 0.283), frequency of seizure before treatment (PCS p: 0.648; MCS p: 0.213), frequency of seizure after treatment (PCS p: 0.249; MCS p: 0.407), and frequency of seizure within the last 1 year were not significant to influence the QoL (PCS p:0.978; MCS p: 0.513). This result was paralel to study by Tlusta, et $\mathrm{al}^{18}$ stated type of seizures had no significant association, but was contradiction to many previous studies.

Correlation analysis revealed that QOLIE-89 total score was negatively correlated with seizure severity, type of seizure, and seizure frequency $(\mathrm{r}=-0.424,-0.145$, and -0.274 respectively, $\mathrm{p}<0.01) .{ }^{19}$ Partial seizures associated with poorer QoL. ${ }^{20}$ The analysis of variance showed that the partial epilepsy subgroup had significantly lower averages for all the QoL subfields except for the social relationship dimension. On regression analysis, having a generalized type of seizure was all related to higher scores on the HRQOL. ${ }^{21}$

Predictors of QoL included epilepsy duration $(\mathrm{p}<0.05) .{ }^{22}$ Epilepsy duration positively correlated with overall QoL only among older adults. ${ }^{23}$ Study in multicentre in Italian showed that duration of epilepsy was still a significant negative predictor of the overall Epi-QoL score in both pairwise model. ${ }^{24}$

Study in Iran stated there was a significant correlation between QoL and frequency of seizures per year. ${ }^{25}$ Cross sectional study in India revealed QOLIE and seizure frequency was found to be statistically significant $(\mathrm{p}<0.01) .{ }^{26}$ Frequency of seizures was the most significant parameter related to QOL $(\mathrm{R}=0.46$ with total score). Duration of disease also correlated with QOL score $(\mathrm{R}=0.24$ with total score). Significant but rather weak association (link) between frequency of seizures and almost all of subscales of QoL was noticed. ${ }^{27}$ Seizure frequency, employability and psychiatric comorbidity were found to be risk factors for QOLIE-31 overall score, accounting for 33\% of the variance in the regression model. The greater seizure frequency were the main factors influencing the quality of life in epileptic patients as evaluated by QOLIE-31.28 Stepwise regression analysis showed that seizure frequency of at least once in three months was a predictive for $\mathrm{QoL} .{ }^{29}$

\section{CONCLUSION}

Family history of epilepsy is the only significant factor contributing to QoL. Type of seizure, duration of epilepsy, history of epileptic status, the presence of neurological deficit, frequency of seizure before treatment, frequency of seizure after treatment, and frequency of seizure within the last 1 year are not significant to influence the QoL. Further research with a large number of subjects and multicenter is crutial to determine the factors that really affect the QoL.

\section{REFERENCES}

1. Sharma S and Dixit V. Epilepsy - a comprehensive review. International Journal of Pharma Research \& Review 2013;2(12):61-80.

2. Banerjeea PN, Filippi D and Hauser WA. The descriptive epidemiology of epilepsy-A review. Epilepsy Research 2009;85:31-45.

3. Mukhopadhyay HK, Kandar CC, Das SK, Ghosh L and Gupta BJ. Epilepsy and its management: a review. Journal of PharmaSciTech 2012;1(2):20-26.

4. Mahrer-Imhof $R$, Jaggi $S$, Bonomo $A$, Hediger $H$, Eggenschwiler P, Krämer G, et al. Quality of life in adult patients with epilepsy and their family members. Seizure 2013;22(2):128-135.

5. Petruzzi A, Rigamonti A, Finocchiaro CY, Borelli P, Lamperti E, Silvani A, et al. Psychological features and quality of life in 50 adult patients with epilepsy and their caregivers from the Lecco epilepsy center, Italy. Epilepsy Behav 2017;71:13-16.

6. Bhalla D, Tchalla AE, Marin B, Ngoungou EB, Tan CT and Preux PM. Epilepsy: Asia versus Africa. Epilepsia 2014;55(9):1317-1321.

7. George J, Kulkami C and Sarma K.Antiepileptic Drugs and Quality of Life in Patients with Epilepsy: A Tertiary Care HospitalBased Study. International Society for Pharmacoeconomics and Outcomes Research (ISPOR) 2015;6C:1-6.

8. Auriel E, Landov H, Blatt I, Theitler J, Marton RG, Chistik V, et al. Quality of life in seizure-free patients with epilepsy on monotherapy. Epilepsi \& Behavior 2009;14(1):130-133.

9. Kanner AM, Barry JJ, Gilliam F, Hermann B and Meador KJ. Anxiety disorders, subsyndromic depressive episodes, and major depressive episodes: do they differ on their impact on the quality of life of patients with epilepsy? Epilepsia 2010;51:1152-1158.

10. Kubota $\mathrm{H}$ and Awaya $\mathrm{Y}$. Assessment of health-related quality of life and influencing factors using QOLIE-31 in Japanese patients with epilepsy. Epilepsy Behav 2010;18:381-387.

11. Kwan P, Yu E, Leung H, Leon T and Mychaskiw MA. Association of subjective anxiety, depression, and sleep disturbance with quality-of-life ratings in adults with epilepsy. Epilepsia 2009;50:1059-1066.

12. Yue L, Yu P, Zhao D, Wu D, Zhu G, Wu X, et al.Determinants of 
quality of life in people with epilepsy and their gender differences. Epilepsy \& Behavior 2011;22(4):692-696.

13. Milovanovic M, Martinovic $Z$ and Toskovic O. Determinants of quality of life in people with epilepsy in Serbia. Epilepsy \& Behavior 2014;31:160-166.

14. Melikyan E, Guekht A, Milchakova L, Lebedeva A, Bondareva I and Gusev E. Health-related quality of life in Russian adults with epilepsy: The effect of socio-demographic and clinical factors. Epilepsy \& Behavior2012;25(4):670-675.

15. Brusturean-Bota E, Coada CA, Buzoianu $A D$ and PerjuDumbrava L. Assessment of quality of life in patients with epilepsy. HVM Bioflux 2013;5(3):82-87.

16. Onwuekwe IO, Unaogu N, Aguwa EN andEzeala-Adikaibe B. Health-related quality of life and its determinants in adult Nigerians with epileptic seizures. Austin J Neurol Disord Epilepsy 2015;2(1):1013

17. Saadi A, Patenaude B, Nirola DK, Deki S, Tshering L, Clark S, et al. Quality of life in epilepsy in Bhutan. Seizure 2016;39:44-48.

18. Tlusta E, Zarubova J, Simko J, Hojdikova H, Salek $S$ and Vlcek J. Clinical and demographic characteristics predicting QOL in patients with epilepsy in the Czech Republic: How this can influence practice. Seizure 2009;18:85-89.

19. Zhao Y, Wu H, Li J, Dong Y, Liang J, Zhu J, et al. Quality of life and related factors in adult patients with epilepsy in China. Epilepsy \& Behavior 2011;22(2):376-379.

20. Shetty PH, Naik RK, Saroja A and Punith K. Quality of life in patients with epilepsy in India. J Neurosci Rural Pract2012;2(1): 33-38.

21. Giray S, Ozenli Y, Ozisik H, Karaca S and Aslaner U. Health- related quality of life of patients with epilepsy in Turkey. Journal of Clinical Neuroscience 2009;16(12):1582-1587.

22. Perue GG, Gayle F, Fraser R and Ali A. Quality of life of patients with epilepsy living in Kingston, Jamaica. Epilepsy \& Behavior $2011 ; 21(1): 23-26$.

23. Canuet L, Ishii R, Iwase M, Ikezawa K, Kurimoto R, Azechi M, et al. Factors associated with impaired quality of life in younger and older adults with epilepsy. Epilepsy Research2009;83(1):58-65.

24. Edefonti V, Bravi F, Turner K, Beghi E, Canevini MP, Ferraroni M, et al. Health-related quality of life in adults with epilepsy: the effect of age, age at onset and duration of epilepsy in a multicentre Italian study. BMC Neurology 2011;11:33.

25. Zamani G, Shiva S, Mohammadi M, Gharaie M and Rezaei N. A survey of quality of life in adolescents with epilepsy in Iran. Epilepsy \& Behavior2014;33:69-72.

26. Shanmukhi S, Sita Jayalakshmi S and Anand B. Factors associated with quality of life in adultepilepsy patients: a hospital based study from South India. Research in Neurology: An International 2015;DOI: 10.5171/2015.766328.

27. Guekht AB, Mitrokhina TV, Lebedeva AV, Dzugaeva FK, Milchakova LE, Lokshina OB, et al.Factors influencing on quality of life in people with epilepsy.Seizure 2007;16:128-133.

28. Tedrus GMAS, Fonseca LC and Carvalho RM. Epilepsy and quality of life: socio-demographicand clinical aspects, and psychiatric co-morbidity. Arq Neuropsiquiatr 2013;71(6):385-391.

29. Chen HF, Tsai YF, Hsi MS and Chen JC. Factors affecting quality of life in adults with epilepsy in Taiwan: a cross-sectional, correlational study. Epilepsy \& Behavior2016;58:26-32.

\section{Authors Contribution:}

RP- Concept and design of the study, manuscript preparation, statistically analyzed and interpreted, critical revision of the manuscript; RDLRS - Preparing firs draft of manuscript, critical revision of manuscript and review of the study; $\mathbf{J}$ - Reviewed the literatur, preparing first draft of manuscript, statistically analyzed and interpreted; ADW-Reviewed the literature,preparingfirst draf of manuscript, collected data, and review of the Study, statistically analyzed and interpreted FB - Reviewed the literatur, preparing first draft of manuscript, collected data.

Work attributed to:

Faculty of Medicine Duta Wacana Christian University, Yogyakarta, Indonesia.

Orcid ID:

Dr Rizaldy Taslim Pinzon- (i) https://orcid.org/0000-0002-3357-9907

Dr Rosa De Lima Renita Sanyasi- iohttps://orcid.org/0000-0002-3616-6796

Dr Andre Dharmawan Wijono- (iD https://orcid.org/0000-0001-7144-6104

Jesisca- (i) https://orcid.org/0000-0001-8394-6181

Dr Fransiscus Buwana- (1) https://orcid.org/0000-0003-3237-2768

Source of Support: Nil, Conflict of Interest: None declared. 